\title{
Conditioned Effects Produced by Naltrexone Doses That Reduce Ethanol-Reinforced Responding in Rhesus Monkeys
}

\author{
Keith L. Williams and James $H$. Woods
}

\begin{abstract}
Clinical trials have shown that naltrexone is effective in treating alcohol dependence; nausea and dysphoria have been reported as "side effects" in many of these studies. In primates, naltrexone reduces reinforced responding for oral ethanol, sucrose, and phencyclidine. This study was designed to determine if naltrexone reduces reinforced responding for various solutions by producing an interoceptive stimulus that may result in a conditioned taste aversion. Four opioid antagonist-naive rhesus monkeys responded for solutions from a two-spout operant panel for $30 \mathrm{~min}$ per day. During a conditioning phase, the monkeys received novel Kool-Aid ${ }^{\circledR}$ solutions paired with either saline or naltrexone $(0.32 \mathrm{mg} / \mathrm{kg})$ given $30 \mathrm{~min}$ before the session. The monkeys then had seven choice sessions between the saline-paired solution or the naltrexone-paired solution. During the conditioning phase, the naltrexone reduced responding after five naltrexone/solution pairings. In addition, a conditioned taste aversion was produced; the naltrexone-paired solution maintained significantly less responding than did the saline-paired solution during the choice phase. In the next phase, the saline and naltrexone were given "unpaired" from any distinct part of the operant session, and another seven choice sessions followed. Naltrexone had no effect when given "unpaired" from the operant session. Then, another conditioning phase was undertaken followed by another series of choice sessions. During the replication of the conditioning, naltrexone reduced responding by the second pairing, although no conditioned aversion was observed in the subsequent choice sessions. Thus, given in the same manner (dose, route, and pretreatment time) as situations in which naltrexone reduces oral ethanol-, sucrose-, and phencyclidine-reinforced responding, naltrexone produced a conditioned taste aversion. These results suggest that naltrexone-induced nausea and its conditioned effects should be considered in naltrexone's effect in alcoholics.
\end{abstract}

Key Words: Opioid Antagonists, Conditioning, Conditioned Taste Aversion, Alcohol, Monkeys.

$\mathbf{T}$ HE ENDOGENOUS opioid system may mediate the reinforcing properties of ethanol. Attenuating ethanolrelated behaviors, naltrexone (NTX) and other opioid antagonists may block ethanol-induced opioid activation. Many studies document the effect of opioid antagonists on ethanol-related behaviors. ${ }^{1}$ For example, in monkeys, NTX decreased ethanol drinking during free access to ethanol., ${ }^{2,3}$ In addition, NTX reduces oral and intravenous ethanolreinforced responding. ${ }^{4,5}$ Also effective in clinical studies of alcohol dependence, NTX reduced craving, increased abstinence, and decreased relapse. ${ }^{6,7}$ NTX is currently being used as an adjunct in treating alcohol dependence.

Although opioid antagonists affect ethanol-related behaviors, the observed effects are not selective for ethanol.

From the Departments of Psychology (K.L.W., J.H.W.) and Pharmacology (J.H.W.), University of Michigan, Ann Arbor, Michigan.

Received for publication September 8, 1998; accepted December 14, 1998.

This work was supported by United States Public Health Service Grant AA-11424.

Reprints requests: Keith Williams, Ph.D., 1301 MSRB III, Department of Pharmacology, University of Michigan, Ann Arbor, MI 48109-0632; Fax: (734)764-7118; E-mail: keithwil@umich.edu

Copyright (c) 1999 by the Research Society on Alcoholism.
Naloxone and NTX reduce many other ingestive behaviors. Early studies showed that naloxone reduced feeding, water consumption, and sucrose drinking in rats. ${ }^{8-10}$ In other studies these antagonists decreased drinking of water as well as sweetened condensed milk in monkeys. ${ }^{11,12} \mathrm{We}$ have previously shown that the same NTX dose that reduced ethanol-reinforced responding also reduced sucrosereinforced responding. ${ }^{5}$ These data suggest that opioid antagonists reduce ethanol-related behaviors by affecting ingestive or consummatory processes in general rather than selectively attenuating the pharmacological basis of ethanol's reinforcing effects.

Opioid antagonists may affect ingestive behaviors by producing nausea. For instance, intravenous naloxone infusions in normal humans increased dysphoria as rated by the Profile of Mood States. ${ }^{13,14}$ In doses that are used to treat alcohol dependence (50-100 mg orally), NTX increased feelings of nausea, light-headedness, and fatigue in normal subjects. $^{15,16}$ Opioid antagonist-induced nausea has been reported in clinical weight loss trials, ${ }^{17,18}$ as well as studies of taste perception and food preferences. ${ }^{19-21}$ Nausea and dizziness are also reported by alcohol-dependent patients when medicated with NTX. ${ }^{6}$ The side effects of nausea and 
dysphoria, although not emphasized when evaluating the NTX/ethanol interactions, may contribute to the therapeutic effects of NTX in alcohol-dependent patients (and also provide a source of problems for compliance). The side effects seem tolerable when people take NTX alone. However, when people take NTX and consume alcohol, they report more nausea, dysphoria, and sometimes vomiting (EM Hill et al., unpublished data). ${ }^{23-25}$ Thus, opioid antagonists may produce a subjective state that dampens ingestive behaviors.

Classical conditioning paradigms can be used to evaluate the conditionable properties of opioid antagonists. In classical conditioning, an "unconditioned stimulus" (toxin) that produces an "unconditioned response" (dysphoria or nausea) is paired with a "conditioned stimulus" (a particular taste). After repeated pairings, the conditioned stimulus alone can elicit the unconditioned response, which is then called the "conditioned response." For example, an opioid antagonist may produce dysphoria and nausea similar to some toxins. When the antagonist's effects are repeatedly paired with a particular flavor, the animal will show an aversion to that flavor even in the absence of the opioid antagonist's effects. Conditioned taste and place aversions have been produced with opioid antagonists administered to rodents. ${ }^{26-28}$ In these conditioning studies, the antagonists were given after access to the solutions, although in most antagonist/ethanol studies the antagonist was given before access to the solutions. In addition, some studies suggest that if the taste stimulus is sufficiently salient, a conditioned taste aversion can be produced by giving the unconditioned stimulus up to $75 \mathrm{~min}$ before the taste stimulus. ${ }^{29,30}$

The purpose of this study was to determine if a pretreatment of NTX would produce a conditioned taste aversion in monkeys. In previous studies, ${ }^{5,31}$ we showed that NTX $0.32 \mathrm{mg} / \mathrm{kg}$ given $30 \mathrm{~min}$ before fluid access reduced oral and intravenous ethanol-reinforced responding, as well as oral sucrose- and phencyclidine-reinforced responding. Using the same dose and pretreatment time in this study, we wanted to characterize the ability of NTX to condition behavior using a conditioned taste aversion paradigm. We also gave NTX "unpaired" with any distinct part of the operant session to show that the NTX effect depends on temporal pairing of NTX administration and the particular solution.

\section{MATERIALS AND METHODS}

\section{Subjects}

Subjects were four adult male rhesus monkeys (Macaca mulatta; weighing 7.6-11.0 kg). The subjects had no prior experience receiving opioid antagonists. In all of the following experiments the "Guide for the Care and Use of Laboratory Animals" (NIH publication, vol. 25, number 28, revised 1996) was followed.

\section{Apparatus}

The animal housing room was on a 12-hr light/dark cycle (lights on at $0630 \mathrm{hr}$, lights off at $1850 \mathrm{hr}$ ). The monkeys were housed in individual cages measuring $64 \mathrm{~cm} \times 72 \mathrm{~cm} \times 85 \mathrm{~cm}$ high. A fluid-delivery panel, similar to that used in other studies, ${ }^{5.32}$ was attached to one wall of each cage during daily sessions. Holes were cut in the cage wall so that two brass spouts on the fluid-delivery panel protruded into the cage $50 \mathrm{~cm}$ from the floor. A stimulus light that could be illuminated red or green was located $3 \mathrm{~cm}$ above each spout. The drinking solutions were contained in $1000-\mathrm{ml}$ plastic bottles attached to the back of the panel. Plastic tubing connected each bottle to the spout valve. The fluid containers were clevated so that the liquid was gravity-fed to the spout valve and delivery was controlled by a solenoid switch. Contact with either spout closed an electrical circuit (drinkometer) and a response was recorded. The stimulus light above the spout flashed when contact was made with the spout. When the reinforcement schedule was satisfied, the solenoid was activated and $0.5 \mathrm{ml}$ of fluid was delivered. Solutions were measured after the session using graduated cylinders to confirm delivery amounts. The experiments were controlled and the data recorded using IBM PCjr microcomputers located in a room adjacent to the housing room.

\section{Procedure}

Experimental sessions were conducted each day at approximately 8 AM. Each session lasted $30 \mathrm{~min}$, during which time the animal could respond and obtain fluid from either of the two spouts. When the spouts were active, the lights above both spouts were illuminated green. The monkeys were reinforced with $0.5 \mathrm{ml}$ of fluid for every four mouth contacts on the spout (reinforcement schedule $=$ fixed ratio 4 or FR4). The reinforcement schedule on each of the two spouts operated concurrently and independently such that the responses on one spout did not alter the number of responses required on the opposite spout. The animals were fed at the end of the day. From a third spout mounted in the back of the cage, water was available from approximately $2 \mathrm{PM}$ to $7 \mathrm{AM}$.

\section{Conditioning Phase}

During the first phase of the experiment, the monkeys were subjected to 3-day conditioning blocks. On the first day, water was available from one spout while $100 \mathrm{~g} /$ liter sucrose mixed with a novel Kool-Aid@ flavor was available from the other spout. On the second day, water was again available from one spout, while the other spout contained $100 \mathrm{~g} /$ liter sucrose mixed with a different, but novel, Kool-Aid flavor. On the third day, water was available from both spouts. This 3-day block was repeated eight times. Thirty minutes before each of these drinking sessions, the monkeys received an intramuscular injection of saline (days 1 and 3) or NTX $0.32 \mathrm{mg} / \mathrm{kg}$ (day 2). Thus, the Kool-Aid flavor on day 1 was paired with saline ("saline-paired solution") while the Kool-Aid flavor on day 2 was paired with NTX ("NTX-paired solution"). Water was not distinctly paired with saline or NTX. For two of the four monkeys, the saline-paired solution was an orange flavor while the NTX-paired solution was a grape flavor. The other two monkeys received grape as the saline-paired solution and orange as the NTX-paired solution. The spout position of the solutions alternated during each block. For example, the saline-paired solution was on the left in block 1 , the right in block 2 , the left in block 3 , etc. The NTX-paired was on the right in block 1 , the left in block 2 , the right in block 3 , etc.

\section{Choice Sessions with Saline-Paired and NTX-Paired Solutions}

After the conditioning phase, the monkeys had access to both the saline-paired and NTX-paired solutions in the absence of pretreatment injections. Water was not available during the session. This condition lasted for 7 days. The side position of the solutions was alternated daily. 


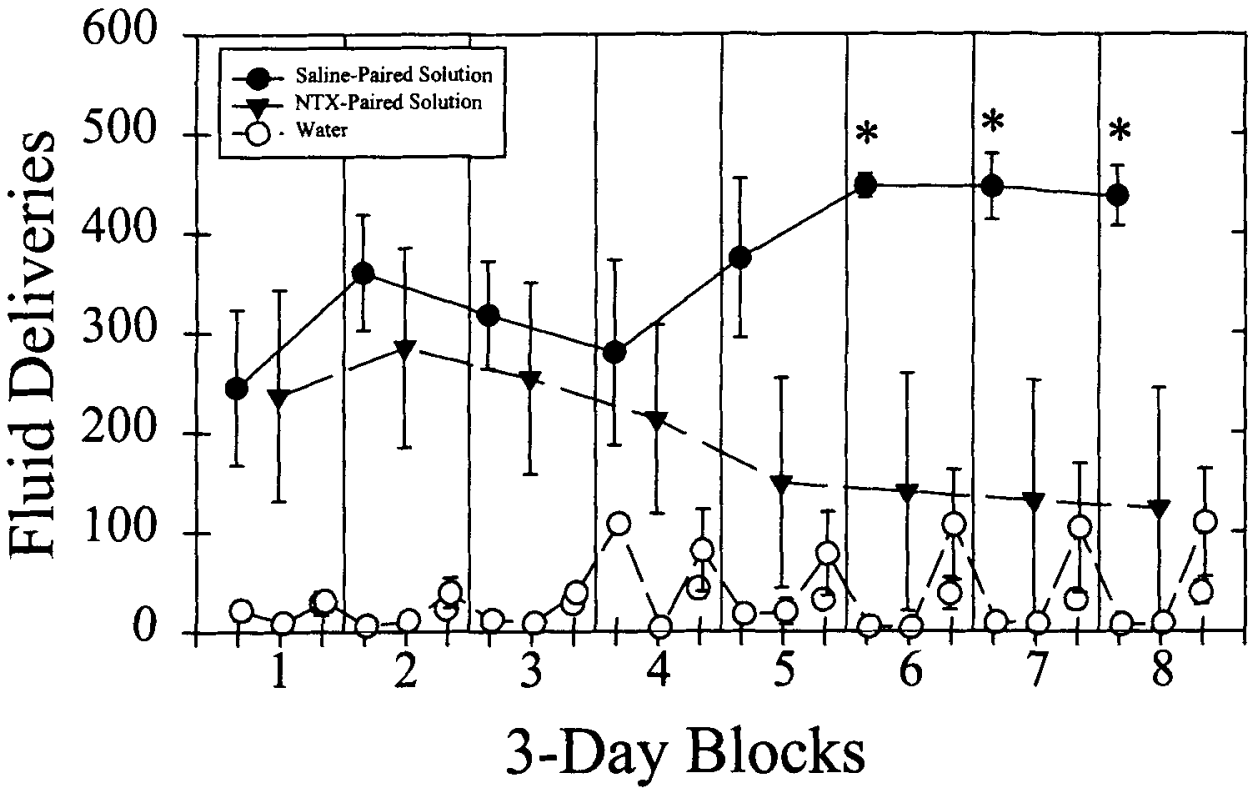

Fig. 1. The average number of fluid deliveries of the saline-paired (filled circles, solid line) and NTX-paired (filled inverted triangles, dashed line) solutions, as well as the concurrently available water (open circles, dashed line) over eight 3-day conditioning blocks. The detached open circles on the third day of each block denote the water available from the second spout when water was available from both spouts. On days 1 and 3 of each block, saline was given $30 \mathrm{~min}$ before the session and on day 2 of each block, NTX 0.32 $\mathrm{mg} / \mathrm{kg}$ was administered at the same pretreatment time. The asterisk indicates a significant difference (Student Newman-Keuls, $p<0.01$ ) between the fluid deliveries of the saline-paired and NTX-paired solutions within the same block.

\section{Choice Sessions with NTX-Paired Solution and Water}

In this condition, the NTX-paired solution was made available concurrently with water in the absence of pretreatment injections. The monkeys were tested for 6 days. The side position of the solutions was alternated daily.

\section{Unpaired NTX Administration}

This part of the experiment was similar to that of the conditioning phase. There were eight 3-day blocks, during which the monkeys received injections of saline (days 1 and 3) or NTX $0.32 \mathrm{mg} / \mathrm{kg}$ (day 2). However, the injections were given at approximately $5 \mathrm{PM}$, which is at least $5 \mathrm{hr}$ after the drinking session ended. In addition, the solution presentation was pseudo-randomized such that the NTX, given on day 2 of each block, was administered $5 \mathrm{hr}$ after access to grape and water (three times), orange and water (three times), and water and water (two times). Also, to avoid producing a side preference, the day 2 Kool-Aid solutions were on the right side three times and on the left side three times. Thus, the NTX was given such that it would be "unpaired" with any distinct aspect of the drinking session.

\section{Choice Test (Saline-Paired and NTX-Paired Solutions)} phase.

This phase is identical to the choice sessions after the conditioning

\section{Conditioning Phase Replication}

This phase is identical to the conditioning phase. One monkey was insensitive to NTXs effects in the original conditioning phase. That monkey's NTX dose was increased to $1 \mathrm{mg} / \mathrm{kg}$ for blocks 6,7 , and 8 .

\section{Choice Sessions with Saline-Paired and NTX-Paired Solutions}

This phase is identical to the choice sessions after the conditioning phase.

\section{Drugs and Solutions}

Kool-Aid solutions were prepared by combining 1 small flavor packet, $200 \mathrm{~g}$ of sucrose, and 2 liters of tap water. All solutions were room temperature during the drinking session. Naltrexone $\mathrm{HCl}$ was supplied by
NIDA, dissolved in sterile water to a concentration of $5 \mathrm{mg} / \mathrm{ml}$, and injected in volumes less than $0.8 \mathrm{ml}$.

\section{Data Analysis}

The data from the conditioning phase and the conditioning-phase replication were analyzed using a two-way repeated measures analysis of variance (within subjects variables- pretreated solution and blocks). All choice tests were analyzed using a two-way repeated measures analysis of varianace (within subjects variables-solution and days). Post hoc Student Newman-Keuls were performed to examine multiple comparisons.

\section{RESULTS}

During the first four blocks of the conditioning phase, the fluid deliveries of the saline-paired solution were approximately equal to those of the NTX-paired solution (Fig. 1). After the fourth block, the fluid deliveries of the NTX-paired solution decreased while the fluid deliveries of the saline-paired solution increased. The interaction effect of the pretreated solution and block approached significance $[F(14,42)=1.88 ; p<0.058]$. The post hoc Student Newman-Keuls test showed that, for blocks 6,7 , and 8 , the fluid deliveries of the NTX-paired solution were significantly less than those of the saline-paired solution $[p<$ $0.006, p<0.004$, and $p<0.005$ ]. By the sixth block, the fluid deliveries of the NTX-paired solution were reduced to 60 deliveries or less for three of four monkeys. NTX had no effect in one monkey which caused the large variability observed from blocks 6 to 8 in Fig. 1. One monkey received fewer than 11 fluid deliveries of the NTX-paired solution on any of the blocks. Thus, repeated NTX-solution pairings reduced the fluid deliveries of that solution over time.

For the first 2 days of choice sessions the fluid deliveries of the saline-paired solution were approximately equal to those of the NTX-paired solution (Fig. 2). There was no significant main effect of solution $[F(1,3)=4.56 ; p<0.12]$ 
Fig. 2. The average number of fluid deliveries of the saline-paired (filled circles, solid line) and NTX-paired (filled inverted triangles, dashed line) solutions available concurrently over the 7 days after the conditioning phase. The asterisk indicates a significant difference (Student Newman-Keuls, $\mathrm{p}<0.05$ ) between the fluid deliveries of the saline-paired and NTX-paired solutions.

Fig. 3. The average number of fluid deliveries of the NTX-paired solution (filied inverted triangles, dashed line) and the concurrently available water (open circles, solid line) over 6 days.
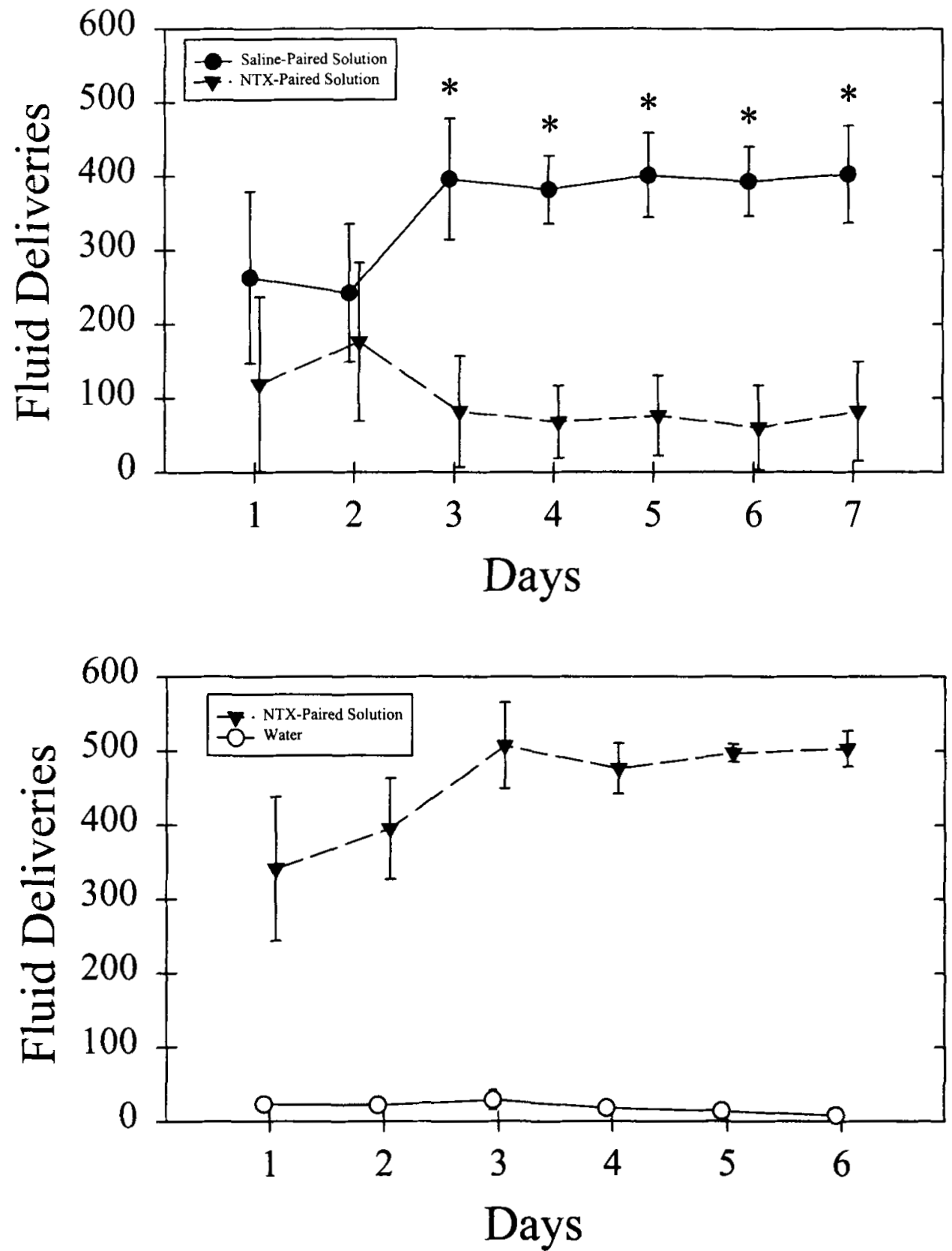

or days $[F(6,18)=0.26 ; p<0.95]$. The interaction effect was also not significant $[F(6,18)=2.12 ; p<0.10]$. However, the post hoc Student Newman-Keuls test indicated that the fluid deliveries of the NTX-paired solution were significantly less than the saline-paired solution during days 3 through $7[p<0.02]$. For two of four monkeys, the fluid deliveries of the NTX-paired solution never exceeded eight fluid deliveries during all the choice sessions. The monkey for which NTX was ineffective during the conditioning phase showed no preference for either solution. Thus, NTX administration before a novel solution access can alter solution preferences and produce a conditioned taste effect.

When the NTX-paired solution was made available concurrently with water (Fig. 3), the fluid deliveries of the
NTX-paired solution were significantly higher than those of water [main effect of solution, $F(1.3)=171 ; p<0.001$ ]. The effect of days and the interaction of solution and days were not significant $[F(5,15)=1.83 ; p>0.18$ and $F(5,15)$ $=1.94 ; p<0.15$ ]. The average data in Fig. 3 suggest that an extinction process took place such that the fluid deliveries of the NTX-paired solution gradually increased over a time when no alternative sweet and caloric solution was made available. Two of the four monkeys showed a more robust extinction pattern. During the first 3 days for these two monkeys, the fluid deliveries of the NTX paired solution gradually increased such that by the third and fourth day the monkeys received more than twice the fluid deliveries they received on day 1.

When NTX was administered unpaired with any distinct 

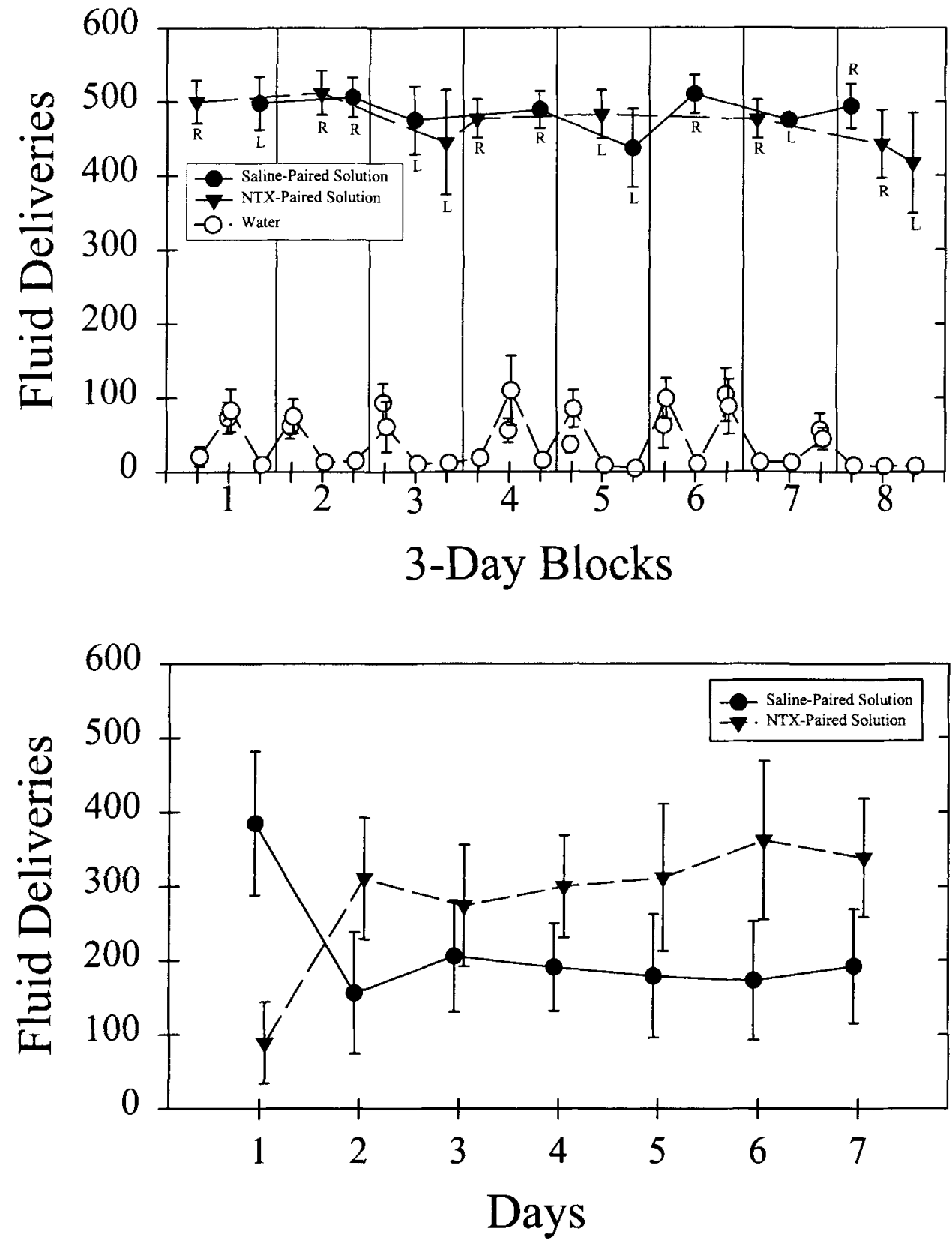

Fig. 4. The average number of fluid deliveries of the saline-paired (filled circles, solid line) and NTX-paired (filled inverted triangles. dashed line) solutions, as well as the concurrently available water (open circles, dashed line) over eight 3-day conditioning blocks. The detached open circles denote the water available from the second spout when water was available from both spouts. On days 1 and 3 of each block, saline was given at the end of the day at least $5 \mathrm{hr}$ after the session. On day 2 of each block, NTX $0.32 \mathrm{mg} / \mathrm{kg}$ was administered at the same time as the saline on days 1 and 3 . The letters near the saline-paired and NTX-paired symbols denote the side position of that fluid $(R=$ right, $L=$ left).
Fig. 5. The average number of fluid deliveries of the saline-paired (filled circles, solid line) and NTX-paired (filled inverted triangles, dashed line) solutions available concurrently over the 7 days after the unpaired NTX administration. part of the operant session (Fig. 4), there was clearly no differential effect of NTX. The fluid deliveries of the previously saline-paired solution were no different from those of the previously NTX-paired solution.

When the monkeys were given choice sessions after the unpaired NTX administration (Fig 5), the fluid deliveries of the saline-paired solution were approximately equal to those of the NTX-paired solution. Two of the monkeys showed a substantial side preference during this phase of the experiment. The side preferences are responsible for the shape of the average data in which the solution that maintains the greatest fluid deliveries alternates every other day. For example, the fluid deliveries of the NTXpaired solution were greater on days 3,5 , and 7 .

During the conditioning phase replication (Fig. 6), the fluid deliveries of the saline-paired solution and NTXpaired solution were approximately equal only on day 1 . Thereafter the fluid deliveries of the NTX-paired solution decreased rapidly. There was a main effect of solution $[F(2,4)=34 ; p<0.004]$, block $[F(7,14)=5.05 ; p<0.005]$, and an interaction of solution and block $[F(14,26)=2.53$; $p<0.02]$. The post hoc Student Newman-Keuls test revealed that fluid deliveries of the NTX-paired solution was significantly less than those of the saline-paired solution from blocks 2 through $8[p<0.04]$. In the original conditioning phase, these solutions were different only from blocks 6 through 8 . During block 1 , the fluid deliveries of both solutions were greater than in the corresponding block of the original conditioning phase. For one monkey the NTX dose was increased to $1 \mathrm{mg} / \mathrm{kg}$ from blocks 6 through 
Fig. 6. The average number of fluid deliveries of the saline-paired (filled circles, solid line) and NTX-paired (filled inverted triangles, dashed line) solutions, as well as the concurrently available water (open circles, dashed line) over eight 3-day conditioning blocks of the conditioning phase replication. The detached open circles on the third day of each block denote the water available from the second spout. On days 1 and 3 of each block saline was given $30 \mathrm{~min}$ before the session and, on day 2 of each block, NTX $0.32 \mathrm{mg} / \mathrm{kg}$ was administered (indicated by "NTX" on the $x$ axis) at the same pretreatment time. The asterisk indicates a significant difference (Student Newman-Keuls, $p<0.05$ ) between the fluid deliveries of the saline-paired and NTXpaired solutions within the same block.

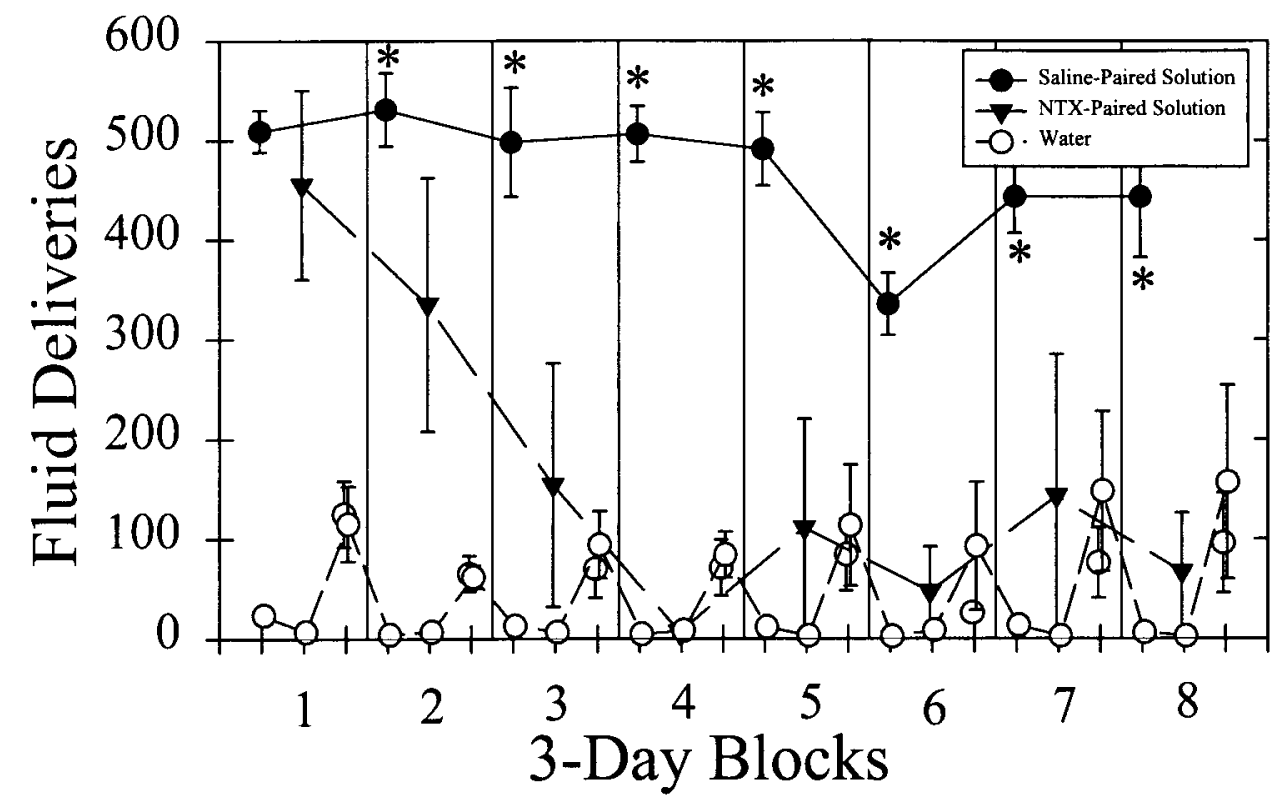

8. This monkey, previously insensitive to the effects of NTX in the original conditioning phase, then reduced responding for the NTX-paired solution. Overall, NTX appeared to have a greater effect during the conditioning phase replication than in the original conditioning phase.

Even though NTX reduced the fluid deliveries of the NTX-paired solution during the conditioning phase replication, the following choice sessions showed that NTX had no effect on solution preference during a time subsequent to the NTX injections. Thus, the second conditioning phase failed to reproduce the conditioned changes to the NTXpaired solution.

\section{DISCUSSION}

In this study, we examined whether NTX would produce a conditioned taste effect when given in the same manner as that which reduces oral and intravenous ethanolreinforced responding as well as sucrose- and phencyclidine-reinforced responding. ${ }^{5,31}$ The results show that, during the original conditioning phase, NTX reduced fluid deliveries on the day of injection only after the fifth conditioning block. After the conditioning phase, the animals showed a preference for the saline-paired fluid rather than the NTX-paired fluid, thus indicating a conditioned aversion to the NTX-paired fluid. When the NTX administration was unpaired with the solution, NTX failed to reduce fluid deliveries on either the day of injection or the day after injection and also failed to produce a conditioned effect. During the replication of the conditioning phase, NTX reduced fluid deliveries on the day of injection more effectively than during the original conditioning phase. These results may help explain how opioid antagonists reduce ethanol drinking.

Opioid antagonists may block ethanol's reinforcing properties and thus suppress ethanol drinking. Some research indicates that opioid antagonists block the ethanol-induced increase of endogenous opioid activity that mediates ethanol's reinforcing properties. ${ }^{33}$ However, there are many arguments against this hypothesis. At doses that affect ethanol drinking, opioid antagonists reduce a variety of ingestive behaviors. ${ }^{34}$ If NTX was blocking the ethanolinduced increase of endogenous opioids, then we must assume that feeding and drinking behaviors increase opioid activity to a similar degree. In previous studies, we found that the same NTX doses reduced responding for oral ethanol, sucrose, and phencyclidine responding. ${ }^{5,31} \mathrm{We}$ also showed that the NTX effect was not surmountable by increasing the ethanol concentration and thus total ethanol intake $(\mathrm{g} / \mathrm{kg})$. Instead, the ethanol concentration-effect curve was shifted down. The ethanol/NTX interaction was not similar to that of an opioid agonist/competitive antagonist interaction in which the antagonist effect is overcome by increasing drug intake. ${ }^{35}$ In addition, large antagonist doses are required to reduce feeding, drinking, and ethanol-related behaviors. This fact, although seldom discussed, suggests that the ethanol/NTX interaction may be due to a mechanism other than blocking ethanol-induced opioid activity. At much smaller doses than those required to reduce ethanol-reinforced responding, NTX blocks opioid-induced antinociception and intravenous opioid self-administration. ${ }^{36,37}$

An alternative mechanism, NTX-induced nausea may be responsible for the effects of NTX on ethanol-related behaviors. This interoceptive state may dampen or reduce ingestive behaviors. Many studies report nausea and dysphoria as a side effect of NTX in nonopiate dependent humans (see Introduction). In this study, we demonstrated that the NTX pretreatment regimen that reduced reinforced responding for ethanol, sucrose, and phencyclidine in our previous study also produced a conditioned taste effect. We used a method by which the conditioned effect 
is assessed by a choice test between the toxin-paired and the vehicle-paired solution. ${ }^{26,27}$ In most conditioned taste aversion paradigms, the toxin is given after exposure to the novel taste stimulus. ${ }^{38}$ However, we gave the NTX before solution access which has also been shown to produce conditioned effects stimulus. ${ }^{29,30}$ Therefore, NTX, as a pretreatment, may reduce ethanol drinking by inducing nausea-related interoceptive stimuli.

Learning plays a role in the suppressant effects of NTX. In the original conditioning phase, NTX reduced responding only after the fifth NTX pretreatment. In the conditioning phase replication, NTX effectively reduced responding for the NTX-paired solution on the second pretreatment day (block 2 ). The monkeys may have reacquired the association between the effects of NTX and the taste of the solution more quickly than the learning that took place in the original conditioning phase. The failure of a conditioned aversion in the choice sessions after the conditioning phase replication may be due to conditional learning. For example, NTX may produce a detectable interoceptive cue when administered alone. When ingesting the solutions in the presence of NTX, the nausea or dysphoria may have increased substantially. Thus, the monkeys may have learned that the aversive experience is conditional upon consuming the solution in the presence of the NTX.

Although it is unlikely that conditioned aversion is the basis of the therapeutic effects of NTX in alcoholics, NTXinduced nausea, or aversive effects may still be important. To produce a conditioned aversion, the taste stimulus should be novel. Alcohol is not a novel taste stimulus to alcoholics and should therefore be ineffective as a conditioned stimulus. NTX also failed to produce aversive effects in all alcohol-dependent subjects. ${ }^{6,7}$ Additionally, if NTX produces an aversion to alcohol, NTX should more effectively reduce "relapse" in subjects that sampled alcohol rather than those that maintained abstinence. One study ${ }^{6}$ showed that NTX improved relapse rates in both the abstainers and the alcohol samplers. However, in the studies that used social drinkers, reports of nausea or aversive effects were greater when the subjects received both NTX and alcohol. ${ }^{22-25}$ Although NTX alone may be an innocuous stimulus in many people, the aversive effects may arise when alcohol is consumed in the presence of NTX. These aversive effects, although not as strong as those produced by disulfiram, may inhibit further alcohol drinking without producing a conditioned aversion. The therapeutic effects of NTX on craving and other measures in subjects that maintain abstinence remain to be explained.

Improvements to the design of this experiment may clarify some issues. First, NTX failed to reproduce a conditioned aversion after the conditioning phase replication. We used the same monkeys in all the procedures described herein. Thus, extensive exposure to both the Kool-Aid flavors during the course of the experiments may have blocked reconditioning because the solutions were no longer novel. In conditioned taste aversion experiments, the novelty of the taste stimulus plays a role in the strength of the subsequent conditioned aversion. ${ }^{38}$ Using a different group of monkeys in the unpaired NTX administration or using different novel flavors during the conditioning phase replication may have solved this problem. Another problem is discerning whether NTX produced a conditioned aversion after the original conditioning phase or whether extensive consumption of the saline-paired solution produced a preference for that solution. The animals received more exposure to the saline-paired solution in our experiment although we used a procedure similar to that used by others. $^{26,27}$ Their experiments used a maximum of four $\mathrm{NTX} /$ solution pairings, although we used eight $\mathrm{NTX} /$ solution pairings. In an additional experiment, the conditioning phase could involve only NTX/solution pairings (omitting saline/solution pairings) and the first choice test could involve a choice between the NTX-paired solution and water. Finally, the monkey that was insensitive to NTX may have skewed the data and hindered the determination of statistically significant effects. With only four subjects, one outlier monkey had a profound effect on the data. We cannot explain why this monkey did not respond to NTX in a manner similar to that of the other monkeys.

Thus, the effects of NTX on ethanol-related behaviors may be due to the ability of NTX to condition an aversion. When both the NTX and the solution are novel, the aversive properties of NTX are revealed by producing a conditioned taste effect. NTX may interact with ingestive behaviors to produce nausea and dysphoria. Future experiments may examine alternative conditioning paradigms to further characterize the role of the aversive properties of NTX in ethanol-related behaviors.

\section{ACKNOWLEDGMENTS}

We thank Joe Duchamp, Charlene Little, and Andrea Cirrito for technical assistance.

\section{REFERENCES}

1. Ulm RR, Volpicelli JR, Volpicelli LA: Opiates and alcohol selfadministration in animals. J Clin Psychiatry 56:5-14, 1995

2. Kornet M, Goosen C, Van Ree JM: Effect of naltrexone on alcohol consumption during chronic alcohol drinking and after a period of imposed abstinence in free-choice drinking rhesus monkeys. Psychopharmacology 104:367-376, 1991

3. Myers RD, Borg S, Mossberg R: Antagonism by naltrexone of voluntary alcohol selection in the chronically drinking macaque monkey. Alcohol 3:383-388, 1986

4. Altshuler HL, Phillips PE, Feinhandler DA: Alteration of ethanol self-administration by naltrexone. Life Sci 26:679-688, 1980

5. Williams KL, Winger G, Pakarinen ED, Woods JH: Naltrexone reduces ethanol- and sucrose-reinforced responding in rhesus monkeys. Psychopharmacology 139:53-61, 1998

6. O'Malley SS, Jaffe AJ, Chang G, Meyer RE, Rounsaville B: Naltrexone and coping skills therapy for alcohol dependence. Arch Gen Psychiatry 49:881-887, 1992

7. Volpicelli JR, Alterman AI, Hayashida M, O'Brien CP: Naltrexone in 
treatment of alcohol dependence. Arch Gen Psychiatry 49:876-880, 1992

8. Holtzman SG: Behavioral effects of separate and combined administration of naloxone and d- amphetamine. J Pharmacol Exp Ther 189: 51-60, 1974

9. Maickel RP, Braude MC, Zabik JE: The effects of various narcotic agonists and antagonists on deprivation-induced fluid consumption. Neuropharmacology 16:863-866, 1977

10. Stapleton JM, Ostrowski NL, Merriman VJ, Lind MD, Reid LD: Naloxone reduces fluid consumption in water-deprived and nondeprived rats. Bull Psychonomic Soc 13:237-239, 1979b

11. Brown DR, Holtzman SG: Narcotic antagonists attenuate drinking induced by water deprivation in a primate. Life Sci 28:1287-1294, 1981

12. Locke KW, Brown DR, Holtzman SG: Effects of opiate antagonist and putative mu- and kappa-agonist on milk intake in rat and squirrel monkey. Pharmacol Biochem Behav 17:1276-1279, 1982

13. Pickar D, Cohen MR, Naber D, Cohen RM: Clinical studies of the endogenous opioid system. Biol Psychiatry 17:1243-1276, 1982

14. Cohen MR, Cohen RM, Pickar D, Weingartner H, Murphy DL: High-dose naloxone infusions in normals. Arch Gen Psychiatry 40:613619,1983

15. Mendelson JH, Ellingboe J, Keuhnle JC, Mello NK: Effects of naltrexone on mood and neuroendocrine function in normal adult males. Psychoneuroendocrinology 3:231-236, 1979

16. Crowley TJ, Wagner JE, Zerbe G, Macdonald M: Naltrexone-induced dysphoria in former opioid addicts. Am J Psychiatry 142:1081-1084, 1985

17. Atkinson RL, Berke LK, Drake CR, Bibbs ML, Williams FL, Kaiser DL: Effects of long-term therapy with naltrexone on body weight in obesity. Clin Pharmacol Ther 38:419-422, 1985

18. Malcolm R, O'Neil PM, Sexauer JD, Riddle FE, Currey HS, Counts $\mathrm{C}$ : A controlled trial of naltrexone in obese humans. Int $\mathbf{J}$ Obesity 9:347-353, 1985

19. Bertino M, Beauchamp GK, Engelman K: Naltrexone, an opioid blocker, alters taste perception and nutrient intake in humans. Am J Physiol 261:R59-R63, 1991

20. Hetherington MM, Vervaet N, Blass E, Rolls BJ: Failure of naltrexone to affect the pleasantness or intake of food. Pharmacol Biochem Behav 40:185-190, 1991

21. Drewnowski A, Krahn DD, Demitrack MA, Nairn K, Gosnell BA: Taste responses and preferences for sweet high-fat foods: Evidence for opioid involvement. Physiol Behav 51:371-379, 1992

22. Deleted in proof.

23. Swift RM, Whelihan W, Kuznetsov O, Buongiorno G, Hsuing H:
Naltrexone-induced alterations in human ethanol intoxication. Am J Psychiatry 151:1463-1467, 1994

24. Davidson D, Swift R, Fitz E: Naltrexone increases the latency to drink alcohol in social drinkers. Alcohol Clin Exp Res 20:732-739, 1996

25. King AC, Volpicelli JR, O'Brien CP, Kreek MJ: Naltrexone pretreatment does not alter reduced neuroendocrine response to alcohol in sons of alcoholics. Research Society on Alcoholism Abstracts, Alcohol Clin Exp Res 21(Suppl):32A, 1997

26. Stolerman IP, Pilcher CWT, D'Mello GD: Stereospecific aversive property of narcotic antagonists in morphine-free rats. Life Sci 22:17551762,1978

27. Mucha RF, Herz A: Motivational properties of kappa and mu opioid receptor agonists studied with place and taste preference conditioning. Psychopharmacology 86:274-280, 1985

28. Mucha RF, Walker MJK: Aversive property of opioid receptor blockade in drug-naive mice. Psychopharmacology 93:483-488, 1987

29. Franchina JJ, Dietz S: Taste aversion following backward conditioning procedures in preweanling and adult rats. Dev Biol 14:499-505, 1981

30. Franchina JJ: Effects of flavor salience on aversion performance following relatively long-delay backward conditioning. Behav Neural Biol 51:127-135, 1989

31. Williams KL, Pakarinen EP, Woods JH: Quadazocine decreases reinforced-responding for oral ethanol, sucrose, and phencyclidine: Comparison to naltrexone effects. Psychopharmacology (in press)

32. Meisch RA, Henningfield JE, Thompson T: Establishment of ethanol as a reinforcer for rhesus monkeys via the oral route: Initial results. Adv Exp Med Biol 59:323-342, 1975

33. Gianoulakis C, de Waele JP: Genetics of alcoholism: Role of endogenous opioid system. Metab Brain Dis 9:105-131, 1994

34. Reid LD: Endogenous opioid peptides and regulation of drinking and feeding. Am J Clin Nutr 42:1099-1132, 1985

35. Winger G, Skjoldager P, Woods JH: Effects of buprenorphine and other opioid agonists and antagonists on alfentanil- and cocainereinforced responding in rhesus monkeys. J Pharmacol Exp Ther 261: 311-317, 1992

36. Rowlett JK, Wilcox KM, Woolverton WL: Self-administration of cocaine-heroin combinations by rhesus monkeys: Antagonism by naltrexone. J Pharmacol Exp Ther 286:61-69, 1998

37. Ko M-C, Butelman ER, Traynor JR, Woods JH: Differentiation of kappa opioid agonist-induced antinociception by naltrexone apparent pA2 analysis in rhesus monkeys. J Pharmacol Exp Ther 285:518-526, 1998

38. Schwartz B, Robbins SJ: Psychology of Learning and Behavior. New York, W. W. Norton \& Company, 1995 